\title{
Analysis of water vapor characteristics of regional rainfall around Poyang Lake using ground-based GPS observations
}

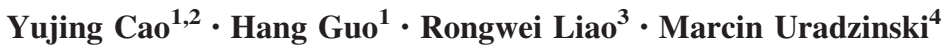

Received: 10 October 2014/Accepted: 22 July 2015/Published online: 30 July 2015

(C) Akadémiai Kiadó 2015

\begin{abstract}
Atmospheric precipitable water vapor of Poyang Lake area can be estimated using the ground-based global positioning system technology and the atmospheric precipitable water vapor change characteristics during the rainfall process can be analyzed. At the same time we can use National Centers for Environmental Prediction reanalysis data and high-density grid data analysis of weather system, water vapor transmission, convergence and precipitation power mechanism. The atmospheric precipitable water vapor and rainfall contrast analysis show that rainfall and precipitable water vapor are not directly in corresponding relation, and their values are not always mutually corresponded. The value of rainfall is closely related with the water vapor transfer and water vapor convergence. In front of the rainfall the increasing process of GPS/PWV changes continuously, and increases suddenly in about $1 \mathrm{~h}$ before the rainfall. The rainfall is not always smaller than the biggest value of GPS/PWV, and has the possibility to be bigger than the GPS/PWV values. GPS delivered PWV could be used to improve the near real time forecast/short term forecast of precipitation.
\end{abstract}

Keywords Water vapor · Rainfall analysis · GPS observations

\section{Introduction}

This paper puts forward the foundation of global positioning system (GPS) technology for atmospheric precipitable water vapor analysis. This developing technology is used for detecting atmospheric water vapor by domestic and foreign scholars. Compared to the

Marcin Uradzinski

marcin.uradzinski@gmail.com

1 Nanchang University, Nanchang, China

2 China Meteorological Administration, Engineering Consulting Center, Beijing, China

3 National Meteorological Information Center, Beijing, China

4 University of Warmia and Mazury in Olsztyn, Olsztyn, Poland 
conventional methods of atmospheric water vapor detection (such as radio sounding, microwave radiometer, satellite remote sensing, etc.). GPS based atmospheric water vapor detection has high precision, high space-time resolution, is an all-weather and near realtime method. It became a powerful tool for the detection of atmospheric water vapor, which is widely used nowadays. GPS techniques for atmospheric water vapor detection are within 1-2 mm of accuracy compared to the conventional methods (Rózsa et al. 2013; Rózsa 2013). Main research direction from the method validation has developed the actual applications, for example the data assimilation of GPS based tropospheric delays (Guo et al. 2000; Yuan 2005), analysis of rainfall process changes (Guo et al. 2009; Li et al. 2008; Ding et al. 2012), or analysis of atmospheric water vapor daily variations ( $\mathrm{Li}$ et al. 2008, 2010).

Poyang Lake is the largest freshwater lake in China. It is located in the "golden waterway" of the Jiangxi Province and belongs to eastern subtropical regions of Eurasia. Climate is a typical monsoon climate. Basin rainfall is rich, with an average annual rainfall of $1620 \mathrm{~mm}$, which has uneven distribution of precipitation seasons by the monsoon climate influence. During spring there is dankness rain, what often changes the temperature of air intersection and produces the frontal rain (with an increased precipitation period). The annual precipitation is concentrated in 4-6 months and $50 \%$ of the annual amount suggests a homogenous rainfall over the whole year. The summer has little rain by the subtropical high control, but it can also produce cloudburst by powerful typhoon in immigration influence. At present, there have been some research in Poyang Lake region about extreme precipitation, weather and climate change, but the study material is based only on conventional meteorological observation data and statistical analysis research. In our research we used Poyang Lake area with foundation of GPS observation data. The authors obtained continuous, real-time, high precision GPS based vapor estimates for the Poyang Lake precipitation process analysis and to forecast the precipitation in the future in the study area.

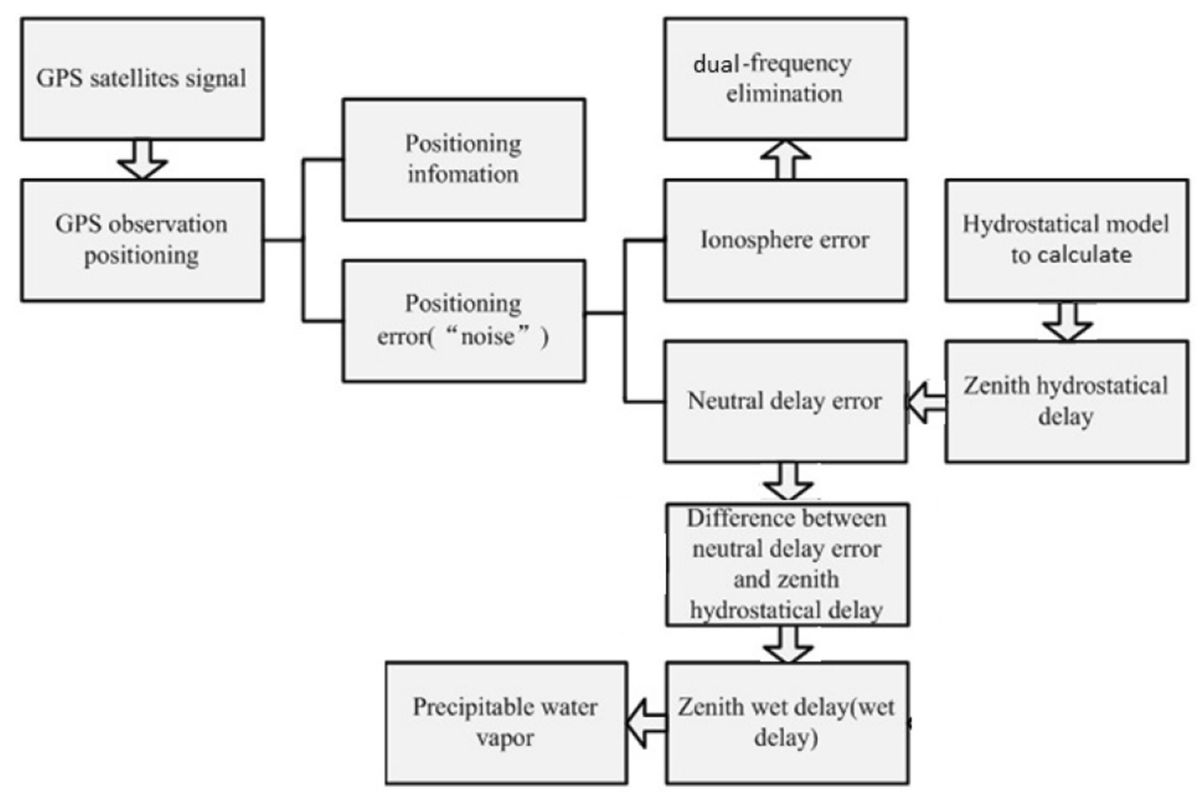

Fig. 1 The flow chart of the ground-based GPS inversion of atmospheric water vapor 
The authors use GPS observations in the Poyang Lake area and invert the tropospheric delays to estimate the water vapor content of the atmosphere to analyze the rainfall process. At the same time, National Centers for Environmental Prediction (NCEP) reanalysis data and high density stations rainfall data can be combined with conventional ground meteorological data for the same purpose. We can analyze the dynamic mechanism and water vapor source which is observed during the period of rainfall precipitation, and the weather system with the influence of the rainfall. This combination can provide a reference for the Poyang Lake area rainfall forecast.

\section{Inversion of tropospheric delays to estimate precipitable water vapor}

The precipitable water vapor (PWV) is the integral of water vapor in an atmospheric column from the topography to the tropopause (Fig. 1). GPS observations can be used to estimate the PWV, thus the basic principles of this technology can be explained here (calculation method):

Calculation of tropospheric zenith total delay is done by the GAMIT software developed by Massachusetts Institute of Technology and tropospheric zenith dry delay was calculated using Saastamoinen model (1):

$$
Z H D=(2.2779 \pm 0.0024) \frac{P_{s}}{f\left(\varphi, H_{s}\right)}
$$

$\mathrm{H}_{\mathrm{S}}$ represents station height above sea level $(\mathrm{m}) ; \mathrm{P}_{\mathrm{S}}$ is ground pressure $(\mathrm{hPa})$; ZHD is zenith dry delay $(\mathrm{mm})$.

The computed ZWD can be scaled down to PWV using the conversion coefficient $\prod$ :

$$
\prod=\frac{10^{6}}{\rho_{w} R_{v}\left[\left(\frac{k_{3}}{T_{m}}\right)+k_{2}^{\prime}\right]}
$$

Fig. 2 The distribution of four GPS stations around the Poyang Lake (Bo 2008)

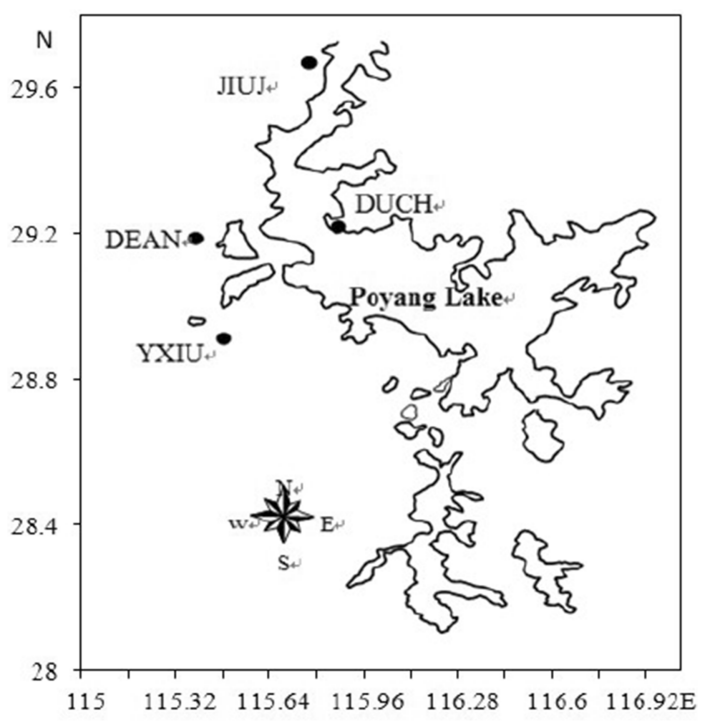


where $\rho_{w}$ is density of liquid water. For experimental constant $\left(\mathrm{k}_{1}=77.6 \mathrm{~K} \mathrm{hPa}^{-1}\right.$, $k_{2}^{\prime}=71.92 \mathrm{~K} \mathrm{hPa}^{-1}, \mathrm{k}_{3}=3.754 \times 10^{5} \mathrm{~K}^{2} \mathrm{hPa}^{-1}$ ), for dry air gas constant, for tropospheric atmospheric weighted average temperature (K). Bevis et al. (1994) presents a formula for the computation of $\mathrm{T}_{\mathrm{m}}$ as a function of the surface temperature.

\section{Observations}

In this project, some local GPS observations were used. Four stations were selected including Duchang Poyang Lake (DUCH), Jiujiang (JIUJ), DeAn (DEAN), and Yongxiu (YXIU) (as shown in Fig. 2) and at the same time, the IGS permanent stations Kunming, Lhasa, Xian were used, too. Using these observations, the PWV in the Poyang Lake area can be estimated. Inversion time is in 2011 (from June 4, at 8 a.m. to June 6, at 8 p.m.). Selecting NCEP reanalysis grid point data for weather process is analyzed. The PWV calculated using the NCEP reanalysis data (referred to as the NCEP/PWV), and the PWV estimated using GPS observations (referred to as the GPS/PWV), what gives us a comparison. NCEP grid point spacing is $1^{\circ}$ by $1^{\circ}$, latitude range is from $25^{\circ} \mathrm{N}$ to $30^{\circ} \mathrm{N}$. Longitude range is from $113^{\circ} \mathrm{E}$ to $118^{\circ} \mathrm{E}$. Time resolution is $6 \mathrm{~h}$. High-density daily precipitation grid point data is used to analyze actual rainfall process in Jiangxi, and the data comes from the National Meteorological Information Center. Conventional surface observations of the site's temperature, pressure is used as parameters of formula (2) to
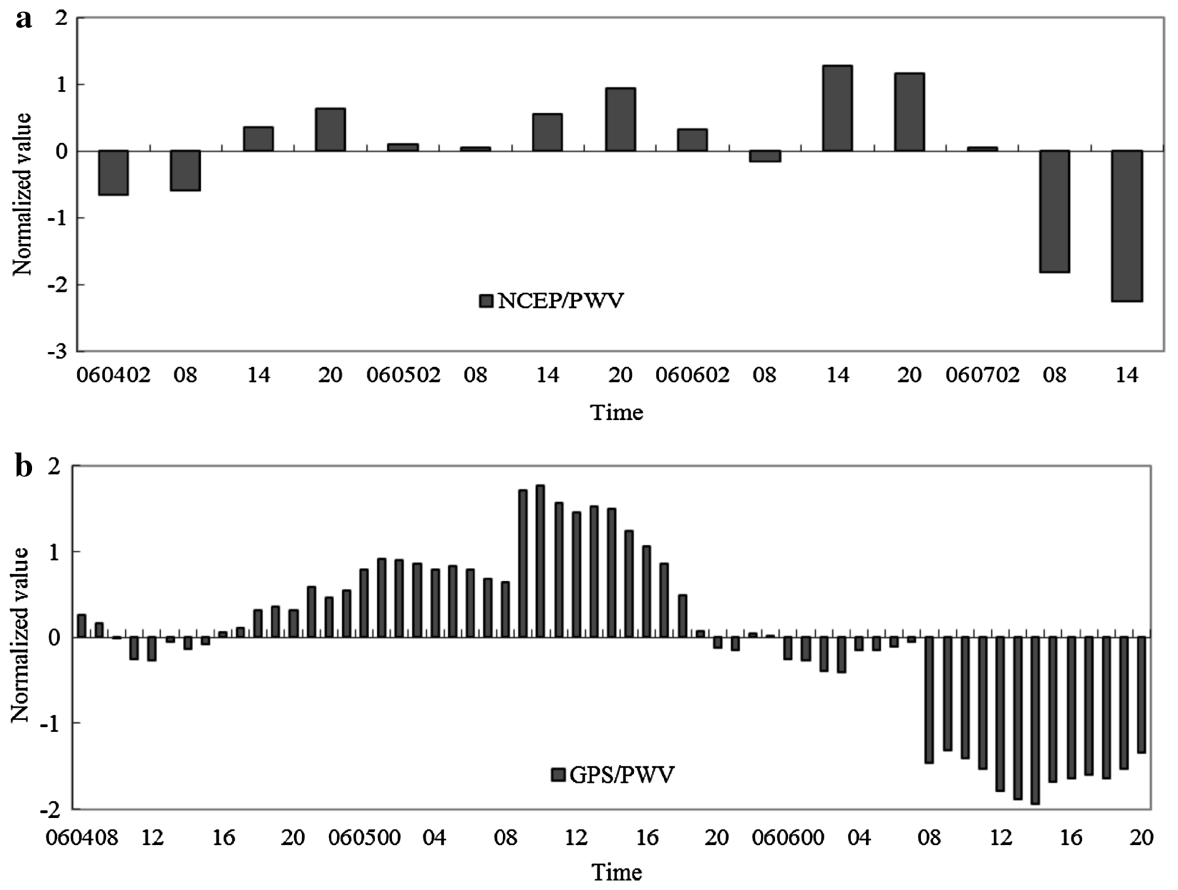

Fig. 3 Diagram a is a NCEP data for the calculation of the atmospheric precipitation (standardized time profile). Diagram $\mathbf{b}$ is GPS inversion of the atmospheric precipitation and can be also standardized time profile 
calculate the GPS/PWV, which also comes from the National Meteorological Information Center.

\section{Analysis of the results}

\subsection{Analysis of GPS/PWV results}

Ground-based GPS observation data inversion used in the analysis ( $1 \mathrm{~h}$ resolution) of the atmospheric water vapor in the Poyang Lake area and at the same time NCEP PWVs are calculated. The NCEP reanalysis data is a gridded dataset, while GPS based PWV is given at the GPS site. In order to compare the two dataset, both of the datasets are normalized.

Figure 3a presents NCEP reanalysis data for the calculation of the Poyang Lake area atmospheric water vapor with standardized time pattern (from June 42 a.m. to June 7, 2 p.m., time interval is 6 h). Figure 3 b shows Poyang Lake area atmospheric water vapor with standardized time pattern which is the result obtained from GPS inversion (from June 4, 8 a.m. to June 6, 8 p.m., time interval is 1 h). Between June 4, 4 p.m. and June 6, 6 a.m., the standardized GPS/PWV and NCEP/PWV values were roughly consistent. The inconsistent before June 4, 4 p.m. and after June 6, 8 a.m. is mainly due to the GPS/PWV and NCEP/PWV calculation range difference. The NCEP/PWV is representative of Poyang Lake, which is the regional average. GPS/PWV is given based on station average, and GPS/PWV time resolution is high, therefore there is a difference between them.

In order to contrast GPS/PWV results further, Fig. 4 gives the June 4, 5, 6 days the NCEP/PWV in Jiangxi Province and the surrounding areas. The approximate Poyang Lake area range is marked on these figures. From 4 to 6 NCEP/PWV profile can be seen above,
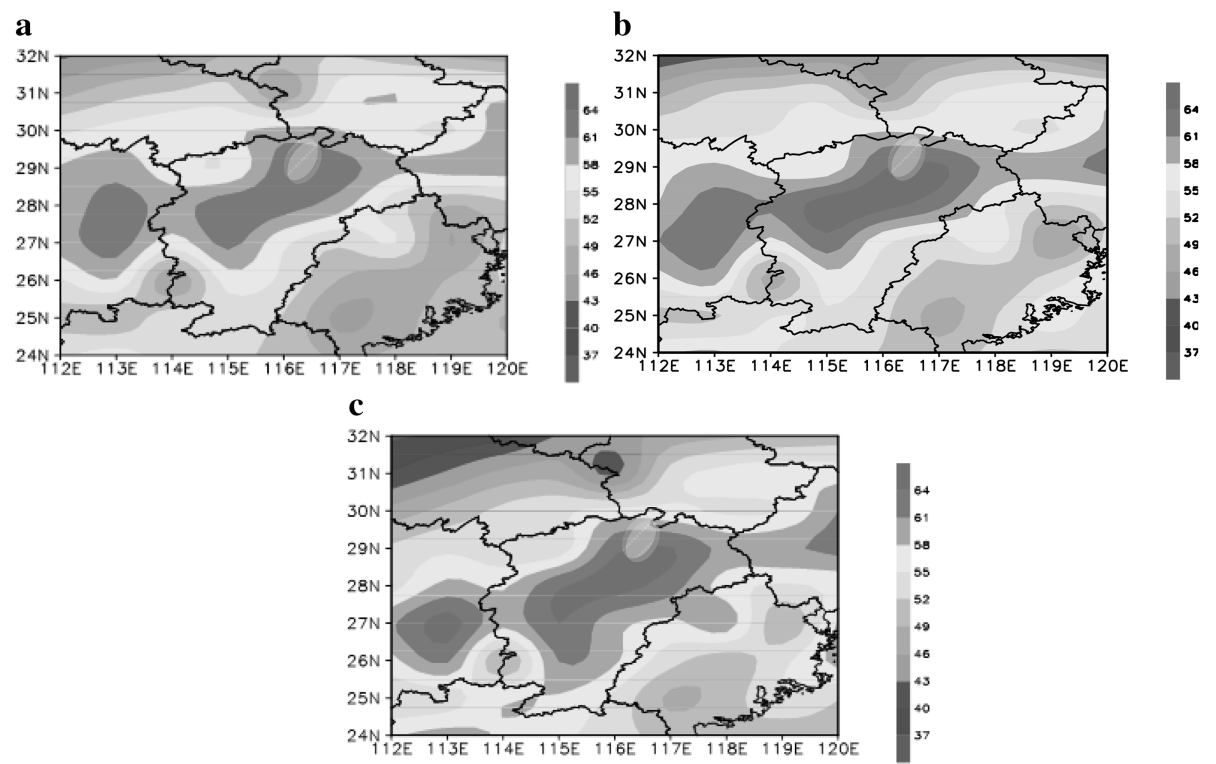

Fig. 4 NCEP atmosphere precipitation pattern. Diagram a b, and c represent respectively the June 4, 5, 6 atmospheric precipitation distribution. Colour scale units: $\mathrm{mm}$. (Color figure online) 
the precipitation value area is located in Jiangxi Province. In June 4 maximum center is weak and the level is above $60 \mathrm{~mm}$. In June 5 center strength increases and reaches above $64 \mathrm{~mm}$. The Poyang Lake district is located in the precipitation maximum area. In June 6 the strongest center moves to the south, but it maintains strong. Poyang Lake area precipitation still shows that the regional air column maintains strong and water vapor is beneficial to the production of strong precipitation.

Figure 5 shows the Poyang Lake based on GPS/PWV time series (from June 4th, 8 a.m. to June 6 th, 8 p.m.). GPS/PWV time series are consistent and 3 days of atmospheric water vapor values are always above $58 \mathrm{~mm}$. It shows that observation period over Poyang Lake in the atmospheric water vapor content is larger with more sufficient water vapor. Based on the June 5th, the phenomenon of precipitation is increased, the maximum reaches $71.5 \mathrm{~mm}$, in June 6th, the atmospheric water vapor decreases, but it is still above $58 \mathrm{~mm}$. On Figs. 4 and 5, we can see that GPS/PWV and NCEP/PWV time change is consistent.

\subsection{The relationship between GPS/PWV and the rainfall}

We used the data of high-density grid points to obtain the daily rainfall what is actually happening at each Poyang Lake measuring station from June 3th to June 8th, to compare with GPS/PWV of each Poyang Lake measuring station and analyze the relationship between them. Figure 6 shows the time series of GPS/PWV and the current rainfall.

Figure 6a is the time chart of GPS/PWV and the rainfall at DuChang station. By the result of the rainfall from the data of high-density grid points we can see in chart that there was rainfall at the DuChang station from June 3 to 6 . And on 5th the rainfall reached $57.8 \mathrm{~mm}$ what was the level of rainstorm. On 4th and 6th the daily rainfall was also quite big reaching the level of moderate rain. On 3th and 7th the daily rainfall was low and just reached the level of light rain. On 8th there was no rainfall. We can see that the GPS/PWV of the DuChang station was always quite big in entire observation time. It indicated water vapor over the DuChang station what is sufficient in the observation time, especially the

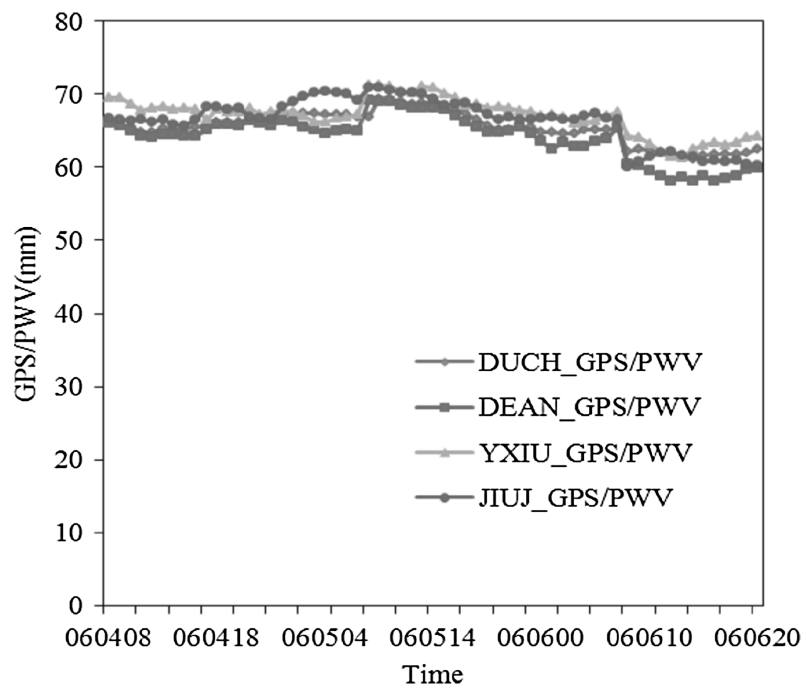

Fig. 5 GPS/PWV precipitation time series 
GPS/PWV when reached $69.4 \mathrm{~mm}$ on 5 th. From the 4th, 8 p.m. to the 5 th 1 a.m., the GPS/ PWV consistently increased. And from the 5th 2 a.m. to 8 a.m., the GPS/PWV began to decrease, but it was still bigger than the 4th's GPS/PWV's measurements. From the 5 th 8 a.m. to 10 a.m. the GPS/PWV increased rapidly, and the increased range reached about $3 \mathrm{~mm}$. Then the rainfall began. After the end of rainfall, the GPS/PWV decreased rapidly, until 4 on the 6th the GPS/PWV increased consistently once again, at 7 on the 6 th it reached the biggest value, and then the rainfall began again. After the end of rainfall on the 6 th, the value of the GPS/PWV significantly reduced, compared with the maximum value on the 5th, the amplitude reached about $8 \mathrm{~mm}$. But the value of the GPS/PWV still maintained above $61 \mathrm{~mm}$. According to the analysis of the time chart of GPS/PWV and the rainfall what is actually happening of the DuChang station, we can see that there were three rainfall processes. The rainfall on the 5 th was the biggest. The value of the GPS/PWV was quite large, always above $61 \mathrm{~mm}$, and on 5th the GPS/PWV was the biggest, what corresponded with the rainfall actually happening.

Figure $6 \mathrm{~b}$ is the time chart of GPS/PWV and the rainfall at JiuJiang station. According to the distribution of the rainfall what is actually happening, we know that there were four rainfall processes in the JiuJiang station from the 3th to the 8th, including three heavy rainfalls on 4th, 5th, and 6th, one light rain on 7th, and no rainfall on 8th. The GPS/PWV's characteristic is similar to the JiuJiang station and the DuChang station, before rainfall, the
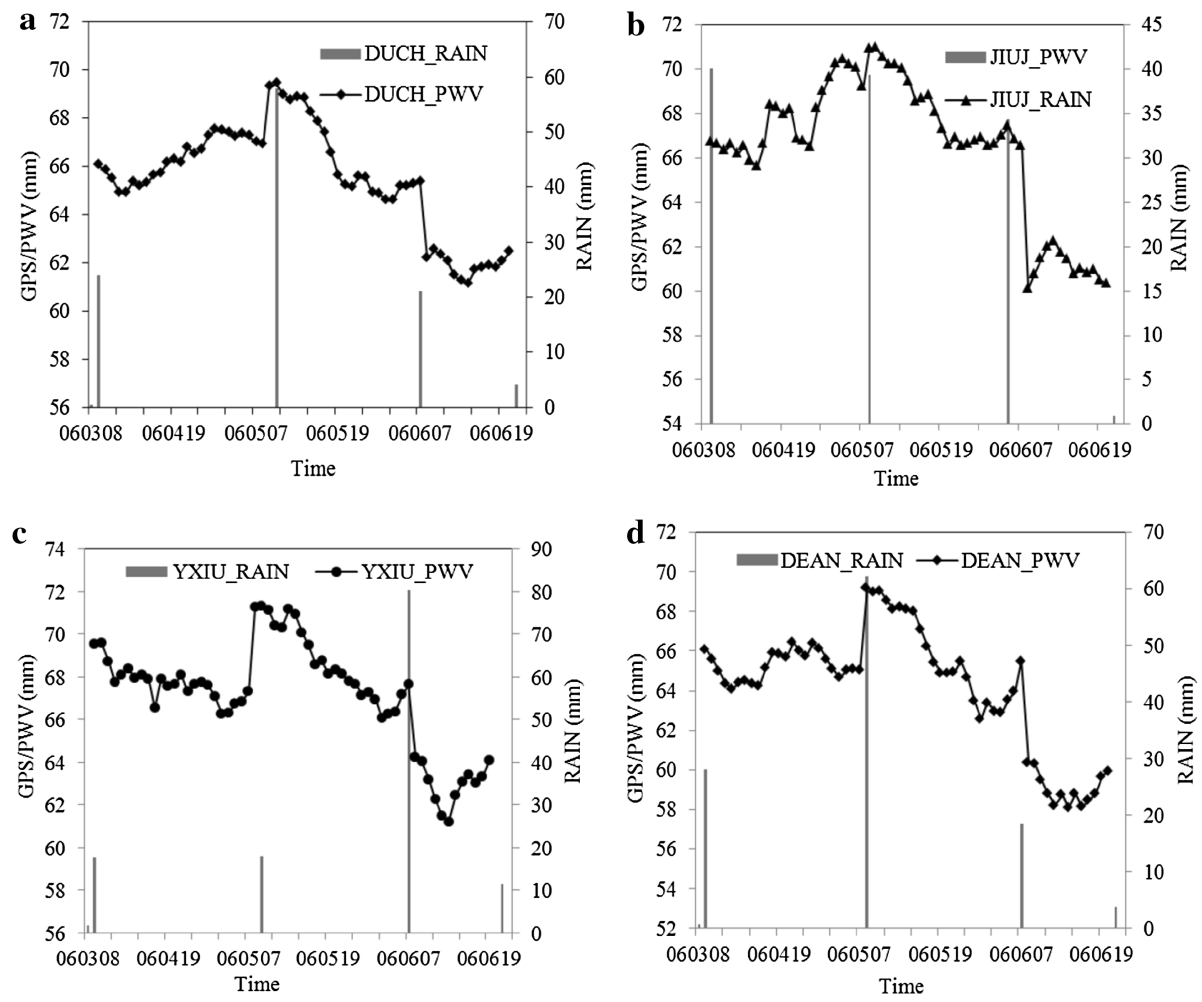

Fig. 6 Charts of the GPS/PWV and the rainfall at DuChang (a), YongXiu (b), JiuJiang (c), and Dean (d) stations 
a
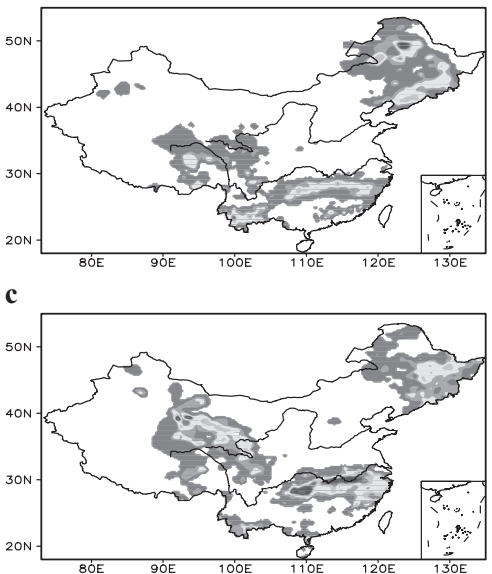

e
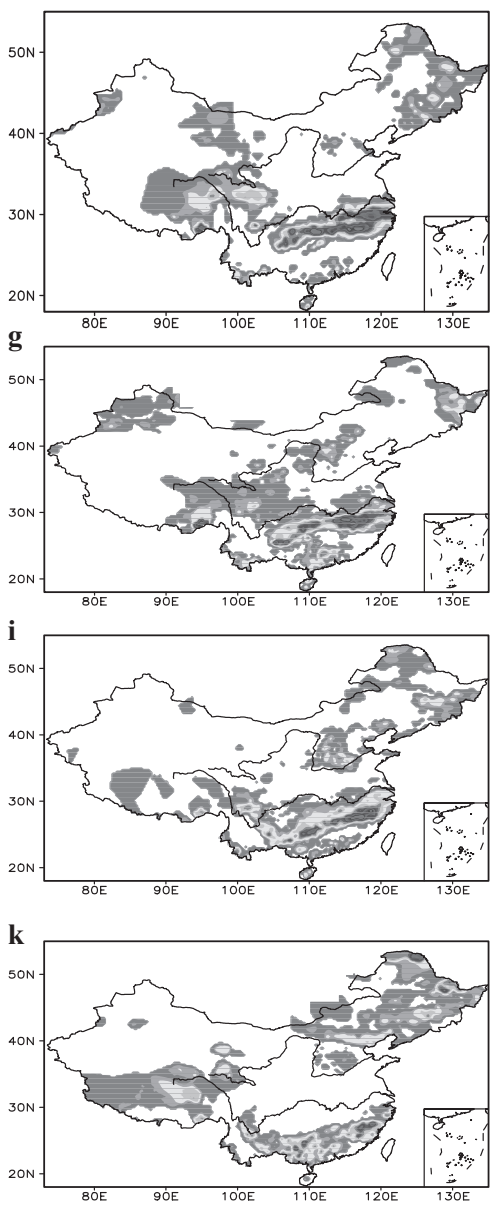

b
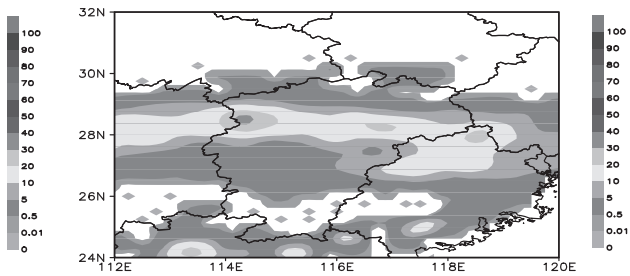

d
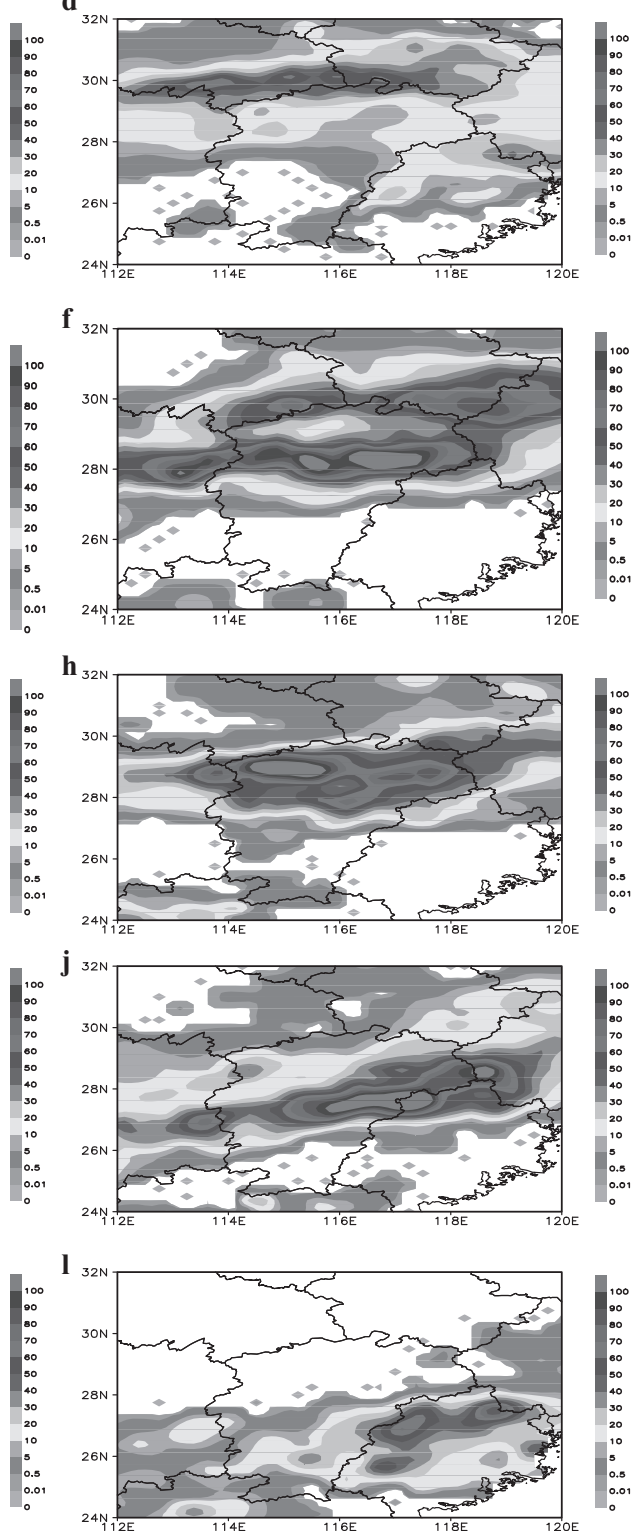
Fig. 7 The daily rainfall distribution map of China and the JiangXi province from 3th and 8th. Color-coded unit: $\mathrm{mm}$. (Color figure online)

GPS/PWV consistently increased, and after the end of the rainfall, the GPS/PWV decreased rapidly. The maximum value of the GPS/PWV concentrated on 5th, but after the end of the rainfall on 6th at the JiuJiang station, its GPS/PWV's reduced amplitude was larger than DuChang's, and the largest reduced amplitude approached $11 \mathrm{~mm}$. Comparing the GPS/PWV results with the rainfall what is actually happening, the JiuJiang station was obviously different from the Duchang station. At DuChang station the large value of GPS/ PWV corresponded with the large value of the rainfall, and at JiuJiang station the large GPS/PWV did not correspond with the large value of the rainfall. The rainfall was about $40.1 \mathrm{~mm}$ on 4th which was larger than it was on 5 th $(39.3 \mathrm{~mm})$. But the average value of the GPS/PWV on 4th at JiuJiang station was approximately $66.8 \mathrm{~mm}$, and the 5th's was approximately $69.1 \mathrm{~mm}$. So, at JiuJiang station the large GPS/PWV value did not correspond with the large value of the rainfall.

Figure $6 \mathrm{c}$ is the time changing chart of GPS/PWV and the rainfall of the YongXiu station. According to the distribution of the rainfall at YongXiu station, there were five rainfalls from the 3 th to the 8 th, including three moderate rainfalls on 4 th, 6 th, and 7 th, one light rain on 3th, and one heavy rainfall on 5th. The GPS/PWV's time change characteristic at YongXiu station is similar with the JiuJiang and the DuChang stations. The maximum value of the GPS/PWV concentrated in the period on 5th, before rainfall, the GPS/PWV consistently increased, and after the end of the rainfall, the GPS/PWV decreased rapidly. Similar to the JiuJiang station, the value of the GPS/PWV at YongXiu station did not correspond with the value of the rainfall. The largest value of the GPS/PWV at YongXiu station on 5th was nearly $72 \mathrm{~mm}$, but the rainfall was just $17.9 \mathrm{~mm}$. The maximum value of the GPS/PWV at YongXiu on 6th was nearly $67.6 \mathrm{~mm}$, however the rainfall was as high as $80.3 \mathrm{~mm}$, which was much larger than the largest GPS/PWV value. This indicated that there was sufficient water vapor supplying.

Figure $6 \mathrm{~d}$ is the chart of GPS/PWV and the rainfall at the YongXiu station changing with time. Looking at the chart, we can realize that the GPS/PWV's characteristics changing with time is similar to the DeAn and the DuChang stations.

Analyzing the characteristics of GPS/PWV and the rainfall of the stations around Poyang Lake changing with time, we can realize that, before rainfall, the GPS/PWV consistently increased, especially within the last hour before rainfall the GPS/PWV suddenly increased and after the end of the rainfall, the GPS/PWV decreased rapidly. The change of the GPS/PWV did not always correspond with the change of the rainfall.

In order to describe the Integral rainfall process in the observation time for the Poyang Lake region further, Fig. 7 has given the rainfall distribution map of China and the JiangXi province which is obtained from the data of high-density grid points. Figure $7 \mathrm{a}-1$ represent respectively the rainfall distribution map of China and JiangXi province on 3th, 4th, 5th, 6th, 7th, 8th of June. From the rainfall distribution map, we can see that not only in the observation time but also before and after the observation time there was a systemic rainfall process which moved from northwest to the southeast, and the time span through JiangXi province was 4-8 days. On 4th the center of the heavy precipitation was located in Yangtze River valley, so that rainfall in the northwest of Jiangxi was large. And on the 5th, the center of the biggest precipitation was located in the boundaries of Jiangxi, the heavy precipitation area covered the Poyang Lake region and the maximum rainfall reached above $100 \mathrm{~mm} \mathrm{day}^{-1}$. This corresponded with the largest value of GPS/PWV on 5th. At the same time, according to the results of the changes of the rainfall what is actually 
happening at every station, there was intense rainfall process on 5th, and it reached torrential rain level at DuChang station. On 5th of June, the center of the biggest precipitation was located in the boundaries of JiangXi, where the heavy precipitation area covered the Poyang Lake region, and the precipitation scope expanded to the south. This corresponded with the large value of the GPS/PWV on 6th at each station. The rainfall on 6th was also quite large, it reached torrential rain level at YongXiu station. Then the rain moved to the southeast, the center of the biggest precipitation moved out of Jiangxi province gradually.

\subsection{Analysis of synoptic situation}

In order to analyze the influence of the weather system to the rainfall, Fig. 8 had given the $500 \mathrm{hPa}$ geopotential height field and the anomalous field of the geopotential height field. From the $500 \mathrm{hPa}$ geopotential height field, we can realize that majority of areas in south of China was the negative anomalous areas which maximum value may reach $10 \mathrm{gpm}$. Combining the geopotential height field in the same day, this indicated that the vice-high tended to East, and the center in Western Pacific was strong. Majority of areas in China were the positive anomalous areas which maximum value may reach above $20 \mathrm{gpm}$. This indicated that the vice-high tended to West on this day, the central crestline lifted to North, and the central intensity had been weakened. Areas in south of China become the negative anomalous areas on 6th. This indicated that the vice-high tended to East on this day, and

$\mathbf{a}$

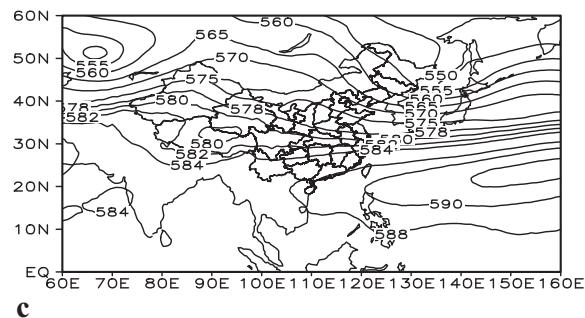

c

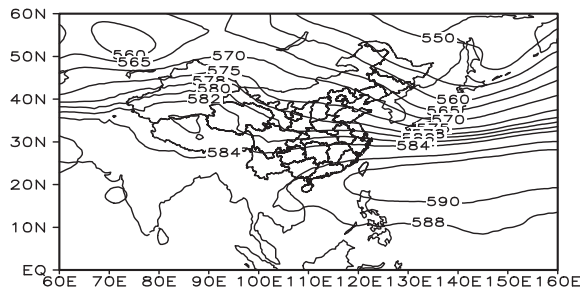

e

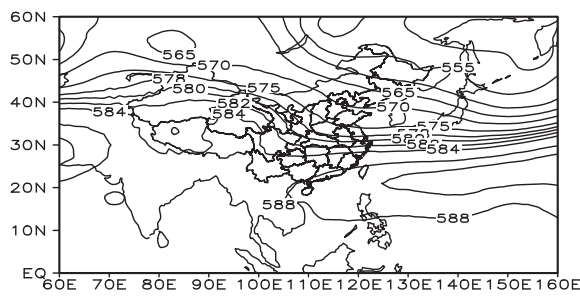

\section{b}

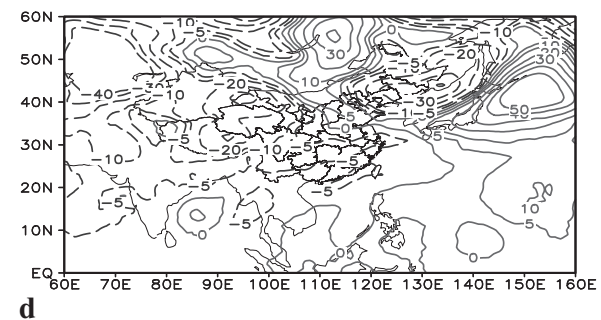

d

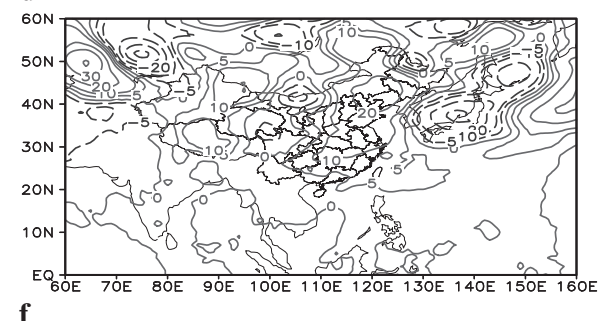

$$
\text { f }
$$

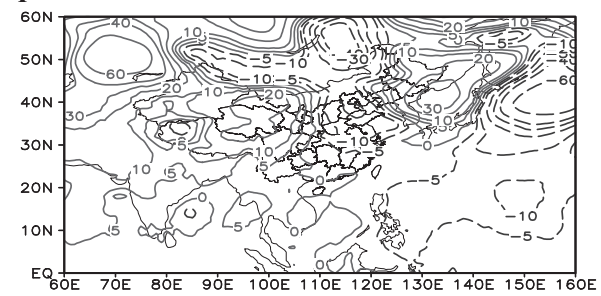

Fig. 8 The $500 \mathrm{hPa}$ geopotential height field and the anomalous field of the geopotential height field (unit: gpm) 
the central intensity had been weaken. We can know that the southern air of the vice-high west side was located in southeast coastal areas. Therefore it was advantageous to the transportation of water vapor to the mainland.

Figure 8a-f represent the $500 \mathrm{hPa}$ geopotential height field and the anomalous field of the geopotential height field of the 4th, 5th and 6th.

\subsection{The analysis of the source of water vapor}

In order to analyze the source of the rainfalls on the 4th, 5th, and 6th, the sufficient supply as an essential condition should be studied. Figure 9 presents the water-vapor transfer field and the water-vapor flux field of divergence. Through the water-vapor transfer field and the watervapor flux field of divergence which was the average of four times a day from June 4 to 6 th, the source of water vapor transported to the south of China was mainly from the water-vapor transfer of the southwest of Bengal Bay and South Chain See and Western Pacific. These three water vapor conveyor belts converged in the southeast coast of China, and transported to the northeast direction. On 4th our country's strongest conveyor belt was located in the Yangtze valley and nearby area, the maximum value may reach $500 \mathrm{~kg} \mathrm{~m}^{-1} \mathrm{~s}^{-1}$ in Jiangxi province. To the corresponded water vapor flux field of divergence, the Yangtze valley and the nearby regions were convergence areas, the maximum value reached $4 \mathrm{~mm} \mathrm{day}^{-1}$ in Jiangxi

a

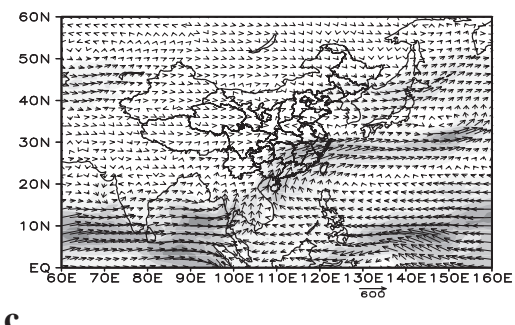

C

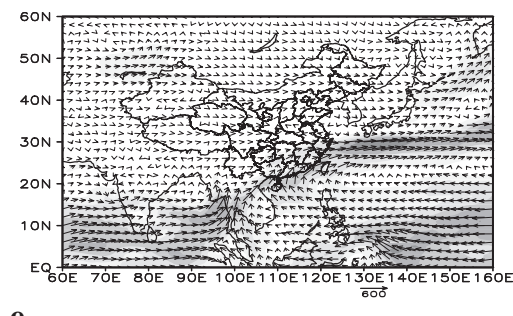

e

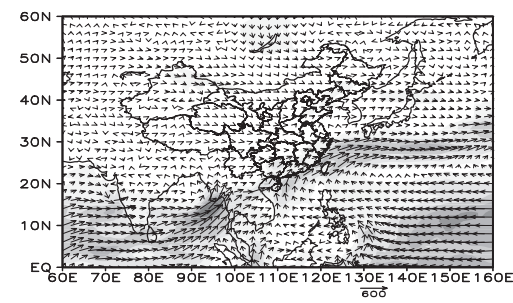

b

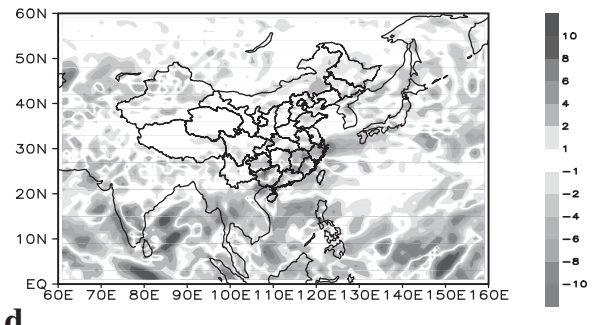

d

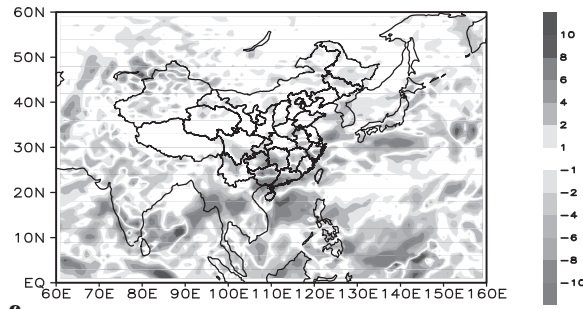

f

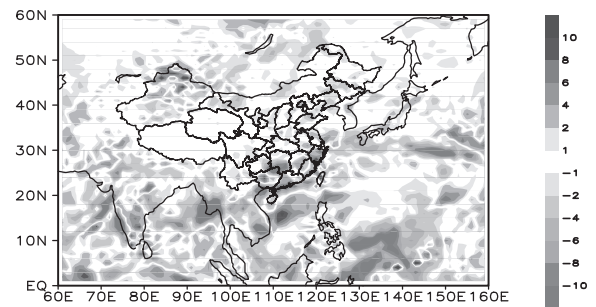

Fig. 9 The water-vapor transfer field (Color-coded unit: $\mathrm{kg} \mathrm{m}^{-1} \mathrm{~s}^{-1}$ ) and the water-vapor flux field of divergence (Color-coded unit: $m$ day $^{-1}$ ). Figures a-f represent 4th, 5th, and 6th of June. (Color figure online) 
province. Because there was sufficient water-vapor transfer and the water vapor collection, therefore it was advantageous for the occurrence of rainfall. This southern conveyor belt moved to the southeast coast of China and close to the sea on 5th. Intensity of southern watervapor transfer was weak in Jiangxi province, so the water vapor flux convergence area moved to the south and the rainfall area moved to the south. This southern conveyor belt continued moving towards the south of Jiangxi area,the intensity was weak, so the water vapor flux convergence area did not change much. Therefore it was advantageous to the water vapor collection provided the sufficient water vapor for the precipitation.

\subsection{The analysis of precipitation dynamic conditions}

Another essential condition to the rainfall's occurrences is the precipitation dynamic condition. To analyze the precipitation dynamic condition on 4th 5th and 6th, Fig. 10 gave vertical circulation anomalous fields. From the vertical circulation anomalous field, we can see that there was strong anomalous updrafts $112^{\circ} \mathrm{E}-125^{\circ} \mathrm{E}$ in the scope of $112^{\circ} \mathrm{E}-\mathrm{E} 125^{\circ}$ on 4th. In Jiangxi province there were also strong anomalous updrafts which coordinated water vapor inputting. It was advantageous to the water vapor lifting. On the plateau of $97^{\circ} \mathrm{E}$ there were strong anomalous downdrafts, what formed the entire-layer anti-clockwise circulation with strong anomalous updrafts collectively. It was advantageous to the heavy rainfall's occurrence. On 5th, from $120^{\circ} \mathrm{E}$ to $125^{\circ} \mathrm{E}$ anomalous updrafts occurred,and in Jiangxi province it was still strong what provided the dynamic condition of rainfall. On 6th it became anomalous downdrafts in Jiangxi, and scope of $120^{\circ} \mathrm{E}-125^{\circ} \mathrm{E}$ the anomalous updrafts were strong and both rain and heavy rainfall moved to the East.

\section{Summary}

Using GPS observation data to coordinate other observation data for analyzing the rainfall and water vapor characteristics changed in time of Poyang Lake area, the following conclusions can be made:
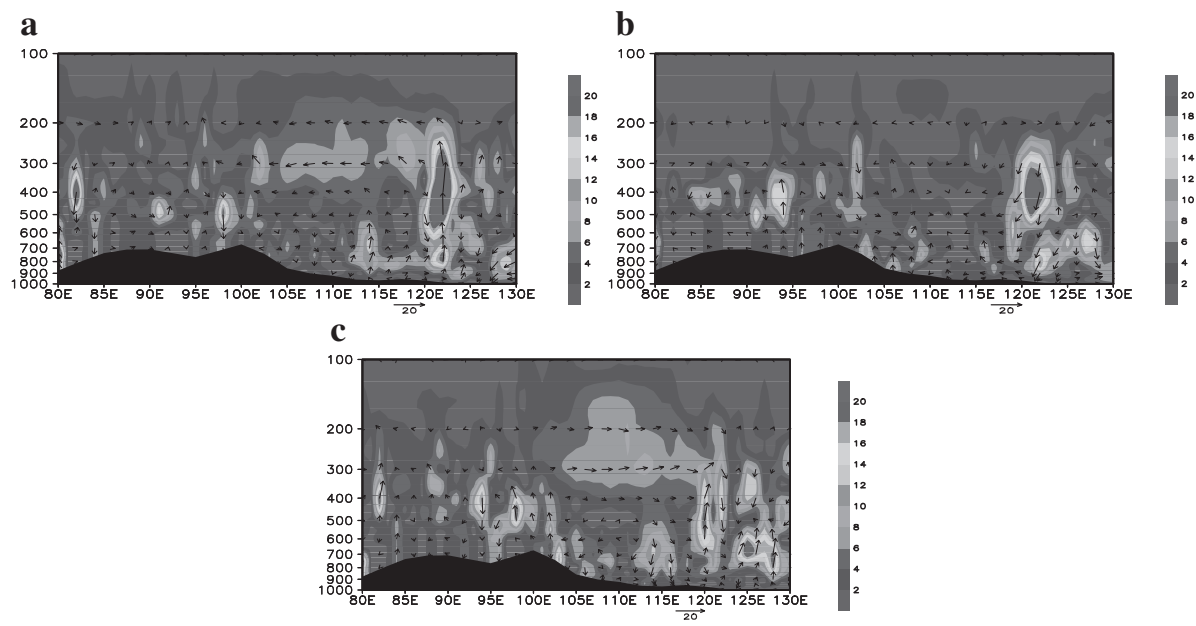

Fig. 10 Vertical circulation anomalous fields (unit: u, v: $\mathrm{m} \mathrm{s}^{-1}$; w:pa, Color code: vertical velocity vector size). (Color figure online) 
(1) Through analyzing the characteristics of GPS/PWV and rainfalls, we realized that the rainfalls do not agree with GPS/PWV directly, and their values are also not always mutually corresponded. The value of rainfall is closely related with the water vapor transfer and water vapor convergence.

(2) Through the analysis we made, it was realized that in front of the rainfall the increasing process of GPS/PWV changes continuously, and increases suddenly in about $1 \mathrm{~h}$ before the rainfall.

(3) The rainfall is not always smaller than the biggest value of GPS/PWV, and has the possibility to be bigger than the GPS/PWV values.

(4) GPS delivered PWV could be used to improve the near real time forecast/short term forecast of precipitation.

\section{References}

Bevis M, Businger S, Chiswell S et al (1994) GPS meteorology: mapping wet delays onto precipitable water. J Appl Meteor 33:379-386

Bo Wu (2008) Distribution and accumulation of heavy metals in the Poyang Lake wetland. Nanchang University, Nanchang

Ding H-Y, Li Q-C, Zheng Z-F (2012) Characteristics of precipitable water of summer rainstorm based on Beijing GPS-MET network. J Appl Meteorol Sci. 23(1):47-58

Guo YR, Kuo YH, Dudhia J (2000) Four-Dimensional variational data assimilation of heterogeneous mesoscale observations for a strong convective case. Mon Weather Rev 128(3):619-643

Guo J, Li G-P, Huang W-S (2009) Characteristics of GPS-retrieved precipitable water vapor in different precipitation types. Adv Water Sci. 20(6):763-768

Li G-C, Li G-P, Lian Z-L (2008a) Features of precipitable water vapor by GPS in different cloudform precipitation - analyses on some typical cases in North China. Plateau Meteorol. 27(5):1066-1073

Li G, Kimura F, Sato T (2008b) A composite analysis of diurnal cycle of GPS precipitable water vapor in central Japan during calm summer days. Theor Appl Climatol. 92(1-2):15-29

Liang H, Liu J-M, Zhang R-H (2010) Diurnal variations of atmospheric water vapor in Lhasa river valley. Adv Water Sci. 21(3):336-341

Rózsa SZ (2013) Uncertainty considerations for the comparison of water vapour derived from radiosondes and GNSS. Int Assoc Geod Symp 139:65-80

Rózsa SZ, Kenyeres A, Weidinger T, Gyöngyösi AZ (2013) Near real-time estimation of integrated water vapour from GNSS observations in Hungary. Int Assoc Geod Symp 139:31-41

Yuan Z-H (2005) Variational assimilation of GPS precipitable water into MM5 mesoscale model. ACTA Meteorol Sin. 63(4):392-404 